Madrygal. Revista de Estudios Gallegos

ISSN: 1138-9664

\title{
Emilia Pardo Bazán como modelo na narrativa galega coeva (1899-1919)
}

\author{
Olivia Rodríguez González ${ }^{2}$
}

Recibido: 7 de novembro de 2021 / Aceptado: 15 de decembro de 2021

\begin{abstract}
Resumo. Ante a cuestión de se a obra e o pensamento de Emilia Pardo Bazán foron asimilados ou rexeitados desde o comezo polo sistema literario galego, este traballo trata de responder amosando como, ao longo da súa traxectoria vital e creativa (1851-1921), a autora foi tida en conta, mesmo con carácter de referente canónico, nos momentos difíciles para os protosistemas narrativos galegos de finais do s. XIX e das primeiras décadas do s. XX. Eses momentos foron tamén decisivos para a prosecución do ronsel rexurdentista, nun caso; e noutro, para a formación do segundo Renacemento cara á definitiva narrativa galega moderna do s. XX. Dúas novelas, de «Xan de Masma» (seudónimo de Patricio Delgado Luaces) e de Vicente Risco, son aquí enfocadas no marco do comparatismo ibérico desde dous títulos de Pardo Bazán, Los Pazos de Ulloa e La sirena negra. Con estas probas tematolóxicas e metanarrativas, así como de filiación a determinadas escolas ou estéticas, etc., conclúese que houbo transferencias sistémicas que tiveron a orixe na posición que Emilia Pardo Bazán ocupaba no parnaso de escritores que estaban a forxar esa narrativa en galego.
\end{abstract}

Palabras chave: Emilia Pardo Bazán; Xan de Masma; Vicente Risco; comparatismo ibérico; novela galega.

\section{[es] Emilia Pardo Bazán como modelo en la narrativa gallega coetánea (1899-1919)}

Resumen. Ante la pregunta de si la obra y el pensamiento de Emilia Pardo Bazán fueron asimilados o rechazados desde el comienzo por el sistema literario gallego, este trabajo trata de responder mostrando cómo, a lo largo de su traxectoria vital y creativa (1851-1921), la autora fue tenida en cuenta, incluso con carácter de referente canónico, en momentos difíciles para los protosistemas narrativos gallegos de finales del s. XIX y de las primeras décadas del s. XX. Esos fueron también momentos decisivos para la prosecución del camino rexurdentista, en el primer caso; y en el otro, para la formación del segundo Renacimiento hacia la definitiva narrativa gallega moderna del s. XX. Dos novelas, de «Xan de Masma» (pseudónimo de Patricio Delgado Luaces) y de Vicente Risco, son los textos que se enfocan aquí, en el marco del comparatismo ibérico, desde dos títulos de Pardo Bazán, Los Pazos de Ulloa y La sirena negra. Se aducen pruebas tematológicas y metaliterarias, así como de filiación a determinadas escuelas o estéticas, etc., para concluir que hubo transferencias sistémicas que tuvieron su origen en la posición que Emilia Pardo Bazán ocupaba en el parnaso de escritores que estaban forjando esa narrativa en gallego.

Palabras clave: Emilia Pardo Bazán; Xan de Masma; Vicente Risco; comparatismo ibérico; novela gallega.

\section{[en] Emilia Pardo Bazán as a Model in the Contemporary Galician Narrative (1899- 1919)}

Abstract. Regarding the question of whether Emilia Pardo Bazán's work and thought were assimilated or rejected by the Galician literary protosystem, this paper attempts to answer by showing how, throughout her life and creative career (1851-1921), the author was taken into account, even as a canonical reference, at difficult times for the Galician narrative protosystems during the late 19th century and the first decades of the 20th century. Those were also decisive times for the continuation of the Rexurdentist path in the first case; and in the other, for the formation of the second renaissance towards the definitive modern Galician narrative of the 20th century. Two novels, by «Xan de Masma» (pseudonym of Patricio Delgado Luaces) and by Vicente Risco, are focused here, within the framework of Iberian comparatism, from two titles by Pardo Bazán, Los Pazos de Ulloa and La sirena negra. Thematological and metaliterary evidence is adduced, as well as evidence of affiliation to certain schools or aesthetics, etc., in order to conclude that there were

1 Traballo realizado no marco do proxecto de investigación The Animal Trope: An Ecofeminist Analysis of Contemporary Culture in Galicia and Ireland / O tropo animal: Unha análise da cultura contemporánea en Galicia e Irlanda (MCIU/AEI/FEDER, UE. 2019-2022. PGC2018-093545-B-I00).

2 Universidade da Coruña. Departamento de Letras.

Correo-e: olivia.rodriguez.gonzalez@udc.es. ORCID: https://orcid.org/0000-0002-2154-589X. 
systemic transfers that originated from the position that Emilia Pardo Bazán occupied in the Parnassus of writers who were forging that narrative in Galician.

Keywords: Emilia Pardo Bazán; Xan de Masma; Vicente Risco; Iberian Comparatism; Galician Narrative.

Sumario. 1. Punto de partida. 2. Unha novela galega na Cuba do s. XIX. 3. Unha novela galega para a modernización narrativa do s. XX. 4. Consideracións finais. 5. Referencias bibliográficas.

Como citar: Rodríguez González, O. (2021): "Emilia Pardo Bazán como modelo na narrativa galega coeva (1899-1919)", en Madrygal. Revista de Estudios Gallegos 24, pp. 239-248, DOI: http://dx.doi.org/10.5209/ madr. 80243 .

\section{Punto de partida}

Neste traballo tentamos disipar dúbidas -se as houber- sobre se a narrativa de Emilia Pardo Bazán influíu ou non na narrativa galega do seu tempo ${ }^{3}$. Escollemos casos que consideramos significativos para comprobar se, na difícil prosecución das letras galegas tras o primeiro Rexurdimento, e durante as primeiras décadas do s. XX, cos ineludibles contextos de reestruturación ou afianzamento do sistema literario español dominante, houbo interferencias sistémicas en relación coa posición que Emilia Pardo Bazán ocupaba no canon español. En concreto, esa posición puido afectar, ou non, á consideración da escritora por parte daqueles escritores e escritoras que estaban a forxar, no cambio de século e tras a Grande Guerra, a narrativa en galego.

Para analizar esta cuestión, vaiamos ao punto de partida, non desde a recepción histórico-crítica actual, senón tal como se foi presentando cando Emilia Pardo Bazán se achaba en plena actividade.

Todos los hombres -escribía Pardo Bazán en 1888 a propósito de se o galego era idioma ou dialecto- somos más obligados á ilustrar y enriquecer la lengua que nos es natural y que mamamos en las tetas de nuestras madres, que la que nos es pegadiza y aprendemos en los libros. (Pardo Bazán 1888: 362)

A escritora citaba literalmente a afirmación expresada por Marcio no Diálogo de la Lengua de Juan de Valdés e que aparecía tamén nos consellos que Don Quijote daba ao Cabaleiro do Verde Gabán no cap. XVI da segunda parte do libro de M. de Cervantes ${ }^{4}$. Pardo Bazán concluía que a lingua das clases cultas en Galicia era o castelán, polo que a linguaxe literaria galega soaba artificial, por estar traducida. A resposta dos escritores da Escola Coruñesa, con Antonio de la Iglesia e Uxío Carré Aldao á fronte, non se fixo esperar: ese idioma nativo era o galego, oculto pola lingua dunha cultura allea. Inda máis: subxace na lingua escrita dos autores que se expresan en castelán (Carré Aldao 1911: 21). Veladamente sinalaba Carré que tamén subxacía na variante dialectal española de Pardo Bazán, por máis que ela se autoimpuxese e perfeccionase co tempo un estilo enxebre (castizo) ao xeito de Galdós, da que é mostra o prestixio literario que o laísmo daquela tiña.

Cando a escritora conmemora, xunto cos colegas membros da Liga Gallega na Coruña, o terceiro centenario en 1905 da primeira parte do Quijote, vese arrodeada de contribucións que lle dan a volta ao seu aserto desafiante de 1888 , co que intentaba invalidar o futuro dunha literatura galega que non se conformase co curral folclórico e aspirase aos froitos refinados da literatura catalá na narrativa (Liga de Amigos de La Coruña 1905). Saíralle mal o agoiro, pois esa mesma tacha soubo ser convertida en acicate polos galegos que seguían o que Murguía chama aforismo político en 1891: "Léngoa distinta (...) acusa distinta nacionalidade", idea que o escritor e historiador galego repetiría no discurso de inauguración da Real Academia Galega en 1906: "El idioma de cada pueblo es el característico más puro y más poderoso de la nacionalidad. Gentes que hablan la lengua que no les es propia, es un pueblo

3 A devandita cuestión entra na polémica xurdida co gallo do centenario do pasamento da autora coruñesa e curiosamente ligada ao seu feminismo, tamén debatido, tal como ilustran dúas obras fundamentais de 2021: Movendo os marcos do patriarcado. O pensamento feminista de Emilia Pardo Bazán, de Marilar Aleixandre e María López Sández (Vigo: Galaxia); e Galicia e feminismo en Emilia Pardo Bazán, de Pilar García Negro (Santiago de Compostela: Alvarellos Editora).

4 "En resolución, todos los poetas antiguos escribieron en la lengua que mamaron en la leche, y no fueron a buscar las extranjeras para declarar la alteza de sus conceptos; y siendo esto así, razón sería se extendiese esta costumbre por todas las naciones, y que no se desestimase el poeta alemán porque escribe en su lengua, ni el castellano, ni aun el vizcaíno, que escribe en la suya" (http://www.cervantesvirtual.com/obra-visor/el-ingenioso-hidalgo-don-quijotede-la-mancha-6/html/05f86699-4b53-4d9b-8ab8-b40ab63fb0b3_13.html\#I_99_[consulta: 04/11/2021]). 
que no se pertenece" (Murguía 1891 e 1906, apud Risco 1976: 79, 130-131).

\section{Unha novela galega na Cuba do s. XIX}

$\mathrm{O}$ primeiro caso de interferencia que presentamos sitúanos ante as novelas galegas publicadas en Cuba no tránsito de séculos, cando a provincia acaba de separarse da metrópole, incapaz de resistir o embate norteamericano que, co pretexto da independencia, sucedía a España no control da colonia. Neste escenario, dous militares dan á luz na imprenta do semanario Follas Novas, de Antonio de P. Cea e Fco. Javier Ramil, senllas novelas en galego desde posicións políticas opostas, pero co tema común dos erros militares, a corrupción administrativa e a decadencia política da metrópole. Trátase do oficial liberal en exercicio, Luis Otero Pimentel, correxidor e alcalde maior de Manzanillo e tenente coronel ao mando do castelo do Príncipe da Habana ata que abandona a illa en 1898; e do antigo combatente carlista de Mondoñedo, Patricio Delgado Luaces, que en outubro de1872 fora detido (Lence-Santar y Guitián 1925) e logo deportado a Cuba tras pasar nove meses no cárcere do castelo de Santo Antón da Coruña.

Hai ligazóns evidentes entre a obra do cervantino Luis Otero Pimentel, Campaña da Caprecórneca, e os escritos de Pardo Bazán sobre a perda de Cuba (Rodríguez 2000: 278-284), pero non imos deternos nelas. Preferimos ocuparnos da segunda das novelas, A besta!, que Patricio Delgado Luaces firma co seudónimo «Xan de Masma», habitual ao pé das súas columnas durante tres anos en Follas Novas, consistentes en artigos, cartas e crítica literaria ocasional. Nunha das recensións precisamente comenta o libro de Luis Otero aparecido en decembro de 1898, tras publicarse no semanario como folletín, co subtítulo Novela gallega, fantásteca e poética. Aclara o crítico na recensión eloxiosa non ter relación ningunha co autor, por moito que el, carlista proscrito, acabara combatendo na illa como voluntario contra a insurrección.

En efecto, enviado a Cuba para loitar co exército español contra os insurxentes, Delgado Luaces deserta antes de entrar en campaña e volve á Península para tomar parte en Euskadi na terceira guerra carlista, onde é ascendido a capitán do exército lexitimista. Unha vez derrotadas, as tropas de Carlos VII exílianse a Francia e cando os oficiais poden regresar cun indulto, descoñecemos que ocorre entón con Patricio Delgado. Parece ser que en 1888 traballa como redactor-xerente de La Voz de la Patria de Madrid. Supomos que regresa despois a Cuba, onde segue con labores na prensa, no comercio e no exército, como comandante de mobilizados (Sánchez Pérez 2011: 2). Nunha nova sobre o seu sepelio no cemiterio de Colón de La Habana, infórmase do nome da esposa, Manuela Santana, así como da súa actividade como socio fundador da Unión Iberoamericana (Redacción Follas Novas 1900).

A novela $A$ besta! iníciase como folletín de Follas Novas en xaneiro de 1899 . O autor compaxínaa cos seus inflamados artigos habituais sobre o fracaso político español e a necesidade de rexeneración de Galicia, sempre atento ao enorme número de galegos establecidos na illa, que están a servir de motor rexionalista e que son os principais destinatarios de Follas Novas, revista de título rosaliano acompañado do subtítulo "Semanario científico, literario y defensor de la colonia gallega" (Vilavedra 1997: 195; Neira Vilas 2011: 51-52). Patricio Delgado Luaces falece con 50 anos o 24 de abril de 1900 (Redacción Follas Novas 1900). As entregas póstumas rematan en decembro, sen que se poida saber se continuaron despois, pois polo de agora eses números do semanario, que segue a publicarse ata 1908, perdéronse, deixando incompleta a novela ${ }^{5}$.

Educado no Seminario de Mondoñedo, formado na carreira de Comercio, gran lector e periodista culto e intelixente -o que non empece o temperamento do que fai gala, ás veces brutal, de combatente que se impón pola razón da forza-, Delgado narra en $A$ besta! a miserable vida labrega nunha comarca da serra do Xistral asoballada por un cacique (alcalde de Mondoñedo) á altura de 1869 e ao longo de oito anos. Nese escenario nace o amor entre Pepa e Pedro, mozo este que na loita contra o tirano e alentado polo crego que lle fai de mentor, se une a unha partida carlista.

Nas iniciais do nome completo do heroe, "Pedro Delgorta", asoma o do propio autor, Patricio Delgado, que ficcionaliza na obra a 
propia biografía. Faino especialmente na segunda parte desta extensa novela, inserindo un diario de combate que se transmite nas cartas que Pedro escribe a Pepa. Deste xeito se narran as peripecias do guerrilleiro carlista que, tras ser detido e encarcerado no Castelo de Santo Antón da Coruña, é deportado a Cuba como parte do exército que loita para esmagar a insurrección. Da illa escapa como desertor e, á volta a España, únese ao exército de Carlos VII en terras vascongadas. Tras a derrota e o exilio en Francia, o protagonista volverá indultado a Galicia, coa prohibición imposta de non achegarse á cidade de Mondoñedo. Casa con Pepa e na aldea de Viveiró pensa poñer en marcha un proxecto de comunidade agraria baseada nos principios do socialismo cristián que impulsara no derradeiro cuarto do século o papa León XIII, desde a encíclica De Rerum Novarum ${ }^{6}$.

Esta parte documental da novela foi utilizada ultimamente como fonte histórica para coñecer as guerrillas carlistas da terceira guerra civil, entre 1872 e 1875 . Neste caso, mesmo quedaron testemuños fotográficos referidos ás guerrillas en Mondoñedo (Lence-Santar y Guitián 1925).

Cada capítulo dispón dun exordio didáctico sobre a situación política e os valores da cultura galega. Esta característica textual, ao tempo que vén xustificada por aparecer o relato nun medio de publicación principalmente sostido e dirixido á colonia galega en Cuba, fai que a obra conecte coa idea que da novela tiñan os románticos alemáns e da que foi modelo o Wilhelm Meister de Goethe (1795-1796): un xénero aberto no que todo cabe, desde ensaio, cartas, diarios, ata poemas líricos. Pero este modelo novelesco queda arruinado en demasiadas ocasións polo excesivo peso panfletario de $A$ besta!, pois como texto de combate ideolóxico que é, con abonda ira, resentimento e mesmo simpleza, carga as tintas tanto no retrato do bando carlista defendido, como no bando liberal demonizado.

Que ten que ver con isto Emilia Pardo Bazán? Ambos os dous escritores coinciden ideoloxicamente no tempo da guerra carlista contra Amadeo de Saboya e a I República pero quedan axiña separados pola afiliación do autor ao rexionalismo de Alfredo Brañas, que nestes anos se aproxima -sen identificarse de todoao carlismo. Que os propios liberais tomasen en consideración a obra de Delgado Luaces, tal como se aprecia nas necrolóxicas que lle dedicaron, debeuse á súa incansable actividade a prol de Galicia. Así, cando mencionaban que fora capitán na terceira guerra carlista, matizaban:

Eso no importa, pues deseaba para su tierra toda clase de reformas. El citado semanario ha dado a conocer un espíritu batallador por lo bello y lo bueno. Publicó su relato, y una escritora cubana y varios escritores gallegos dedicáronle sentida prosa y versos. (Fernández-Merino 1900)

«Xan de Masma» está en débeda coa narrativa de Emilia Pardo Bazán, para empezar, pola escolla dun título tomado de Émile Zola, A Besta! Aínda que o autor advirte no prefacio que non trata de emular un novelista que para el está nas antípodas do seu ideal, presentar unha novela en Galicia de título zoliano significaba seguir o ronsel de Pardo Bazán desde o momento no que ela incorpora á literatura española non o obxectivo (a transformación do mundo eliminando as lacras da sociedade da incipiente $2^{\mathrm{a}}$ industralización) pero si o método da novela experimental: campo de proba e observación onde se desenvolven os personaxes nun marco de determinismo xenético e social, fotografado na súa fealdade e degradación.

Axiña o autor amosa a diloxía contida nese título, pois di referirse á besta de carga que é o traballador galego -convivente (Ramil 1998: 48) por razóns de subsistencia coas bestas cuadrúpedes que lle dan alimento e calor cando chega a fame negra. E tamén alude co termo ao déspota infrahumano representado polo cacique don Policarpo, explotador de homes e depredador de mulleres ao que se lle aplica o tropo da animalización pexorativa:

O brazo do castrón xa rodeaba a cintura da criada.

—Que gorda estás. Dáme un chucho —e o pedazo de cocho empezou a amasar no corpo da

Cf.: https://www.vatican.va/content/leo-xiii/la/encyclicals/documents/hf_1-xiii_enc_15051891_rerum-novarum.html (consulta: 04/11/2021). É un socialismo sui generis, pois preserva a propiedade privada inviolable: "Maneat ergo, cum plebi sublevatio quaeritur, hoc in primis haberi fundamenti instar oportere, privatas possessiones inviolate servandas". De acordo con este principio, varias veces na novela celébrase a magnanidade dos ricos que saben atender as necesidades das bestas labregas. 
xoven, sin que ela puxese máis resistencia que un «estéñase quieto, señor».

Despois levantouse Heleogábalo, e agarrándose ás paredes, pois pesáballe moito o mondondo ${ }^{7}$ co que comera, e a cabeza, co que bebera, foi andando prá cama a roncar de cheo, mentras outros asubiaban de fame. («Xan de Masma» 1993 [1899-1900]: 70)

Por moitos reparos ideolóxicos que apuntase o autor, a filiación da súa novela á corrente de Zola terminaría apoñéndose como causa do descoñecemento durante anos da identidade agochada tras o seudónimo «Xan de Masma». Todo comezou co comentario en nota de Uxío Carré Aldao, na súa Literatura gallega, sobre o respecto á memoria do autor tras a súa recente morte: "Jan de Masma (pseudónimo) que en su obra $A$ Besta, (1) censurando á Zola, incurre en un naturalismo más procaz y en incorrecciones de estilo y léxico imperdonables" (Carré Aldao 1911 [1903]: 119). Coidamos que máis pesaría no esquecemento de Patricio Delgado Luaces o seu inveterado carlismo e a desmemoria das novas xeracións galegas que a suposta incorrección lingüística. Se Carré se refire ao uso incorrecto do galego, iso era común a moitos autores antes da fixación normativa escrita. Máis ben debía de referirse a unha cuestión de decoro. O caso é que foi Xesús Alonso Montero, nun artigo do 12 de abril de 1970 no Faro de Vigo, quen desvelou a identidade do autor, para o cal contara coa colaboración de Vicente Fernández Ares e outros amigos mindonienses, que lle procuraron a partida de bautismo e exemplares de Follas Novas (Alonso 1977; Carballo 1981: 455).

A relación de $A$ besta! con Emilia Pardo Bazán afiánzase no que veremos a continuación. O escritor de Mondoñedo dedica un capítulo a narrar o acontecido na vila durante as eleccións e xorde outra volta como modelo a escritora. Recordemos que Pardo Bazán narraba por primeira vez na literatura española o proceso electoral nunha vila galega -Cebre-e as aldeas da súa circunscrición, na que os $\mathrm{Pa}-$ zos do falso marqués se sitúan. No capítulo XXV de Los Pazos de Ulloa (1886), tras preparar o ambiente en capítulos anteriores co enfrontamento entre os caciques Trampeta e Barbacana, cabezas respectivamente das faccións liberal (gubernativa) e carlista, Emilia Pardo
Bazán leva á novela con intelixencia e grandes dotes de observación o desenvolvemento brutal da violencia caciquil, tanto física como psíquica.

A besta!, pola súa parte, ten o mérito de ser a primeira novela galega que dá relevancia aos sucesos electorais, neste caso, da comarca que se estende de Mondoñedo á serra do Xistral. «Xan de Masma» non explota abondo ese modelo da novelista coruñesa, caracterizado por preciosos matices e eficaces anécdotas que dotan á obra de 1886 dun carácter traxicómico, nas portas do grotesco, liña na que afondaría o seu seguidor Ramón del Valle Inclán. Delgado Luaces non se detén neses pormenores, porque a primeira parte da novela quere ser só estampa de ambiente e costumes, o que non quita valor etnográfico a estas descricións, aínda que non cheguen ao nivel artístico de Pardo Bazán. Á fin e ao cabo, interésalle ao autor agasallar o seu público cunha historia de costumes con estereotipos de folletín, para pasar axiña ao que máis o aprema: o relato do combatente. En efecto, o narrador semella ter présa en abordar a entrada do protagonista Pedro Delgorta, que o relevará como voz narrativa. Así, a partir da superación da derrota militar, todo se encamiña na novela á realización do proxecto de socialismo bo no paraíso do campo galego.

Secasí, non se pode negar que «Xan de Masma» volve situarse no ronsel de Emilia Pardo Bazán, a escritora que narrou a cerna da política electoral en Galicia por vez primeira; e que el sen dúbida continúa e entrega como legado á corrente novelística galega do s. XX, especialmente na pluma de Ramón Otero Pedrayo e de Vicente Risco. O fío non se interrompe ao noso xuízo, porque non é certo que $A$ besta! quedara como obra descoñecida para a posteridade, tal como se adoita repetir (Sánchez Pérez 2011: 217). Non só o semanario que a publicou chegaba a Galicia puntualmente, senón que alén diso, a prensa galega do exterior líase con fruición, e máis se había coincidencia ideolóxica (cf. Redacción El Correo de Lugo 1900).

Apuntemos ao respecto a coincidencia na malleira brutal en ambos os dous escritores: no caso da novelista, ten lugar cando os liberais, borrachos tras o triúnfo nas urnas, fan unha cencerrada ás portas da casa de Barbacana e os secuaces deste cacique, fidalgos e curas carcas, 
saen a golpear con paus e látegos aos contrincantes para resarcirse da humillación.

No caso de $A$ besta!, as malleiras son unha estratexia brutal para evitar que as xentes se acheguen ás urnas e son os liberais, borrachos como cubas tamén, quen as propinan polas rúas de Mondoñedo, acompañándoas de actos sacrílegos na catedral. A continuación, eles son golpeados polos tradicionalistas de Vilaolle. Os xusticeiros do contraataque van encabezados polo cura e entre os seus lugartenentes está o adolescente Xan da Ponte que, como bautizo de sangue, rebéntalle a seseira dunha mocada a un expresidiario asasino - correlato do Tuerto de Los Pazos de Ulloa, "feroz defensor y seide" do avogado Barbacana, de "siniestra catadura" (Pardo Bazán 1999: 292, 287; «Xan de Masma» 1993 [1899-1900]: 80-81).

Por se todo isto non abondase xa para establecer unha filiación clara, a presenza da escritora coruñesa na novela revélase nidiamente nas digresións de «Xan de Masma» sobre o Parnaso galego: no capítulo IV, que pecha a primeira parte, o autor diríxese aos lectores para informalos das "ben talladas prumas" que se ocuparon e ocupan dos galegos: Murguía, Brañas, Curros Enríquez, Pondal, Pintos e tantos outros aos que só lles pon a tacha de que, seica por orixe aristocrática, seica por inclinación ao positivismo, esqueceron os labregos galegos. Fai excepción de Rosalía de Castro, que soubo levar as "queixas dun pobo que agoniza" aos Cantares gallegos. E a seguir escribe:

¿Cómo non falar, xa que teño a pluma na mau, de Emilia Pardo Bazán?

Si este humilde xuício chega astra ela, que non chegará, sepa que a teño pola honra de Galicia; sepa que ademiro a súa portentosa erudición, sepa que os seus escritos máis me parecen de home que de muller non porque elas non sexan capaces coma nós de sentir e de pensar, sinón porque son máis lixeiras, e sabendo todo esto, sepa tamén que coma din que dixo Alfonso o Sabio, emendaríalle a prana a Dios e ise gran talento e ise gran corazón houbérao feito nacere nun berciño máis humilde para que sentira de cerca morriñas dos que non temos cartos para comprar aqueles seus paraiaguas que describe no seu viaxe á Torre de Eiffel; para que entón fora un apóstol convencido como o foi Rosalía. («Xan de Masma» 1900: 142-143)
Probablemente si chegarían ata Emilia Pardo Bazán estas palabras, pois a coruñesa escribía tamén para Follas Novas, publicando, por exemplo no primeiro número de abril de 1900 , o contiño "Cómo será el morir" á beira dunha das entregas de $A$ besta!. Sexa como for, esta mostra indica que para a Galicia literaria do exterior a finais do s. XIX, Rosalía en poesía e Pardo Bazán en novela ocupan no canon unha posición semellante. $\mathrm{O}$ cal revela tamén que a recepción lectora e crítica das dúas escritoras prescinde da distinción entre linguas como lindeiro entre os sistemas español e galego.

\section{Unha novela galega para a modernización narrativa do s. XX}

En 1919 edita Vicente Risco o seu primeiro relato galego co título Do caso que lle aconteceu ao doutor Alveiros. A noveliña aparece en iTerra a nosa!, suplemento do xornal coruñés El Noroeste ${ }^{8}$. Quere contribuír con ela á renovación da narrativa galega dentro do amplo movemento, marcado tanto pola Gran Guerra como pola Revolución Rusa, que inicia a Xeración de 1916 a prol do idioma. Escribira anteriormente contos en cabeceiras como $E l$ Miño e Mi Tierra, ambas de Ourense, liberal unha e tinxida a outra da ideoloxía agrarista de Acción Gallega; así como ensaios en La Palabra (1913) do Ateneo de Madrid, antes de volver frecuentar o Ateneo de Ourense e coincidir alí con Antón Losada Diéguez, que lle dá o pulo para entrar nas Irmandades da Fala a finais de 1917. A partir de 1918 levará a súa orixinal elaboración doutrinal ao nacionalismo galego. No proxecto colectivo do Grupo Nós de crear para sempre a cultura galega contribúe, entre outras achegas, á novela galega cuxo primeiro experimento de seu é este texto orixinariamente escrito en castelán, no que o protagonista parece ser que aparecía co nome de dr. Muñoz (Rodríguez González 2002 [1993]: 34).

El Noroeste era un xornal rexionalista católico da Coruña que os catalanistas de Francesc Cambó fixeron seu durante eses anos. Á beira dos integrantes da devandita Escola Coruñesa, como Eladio Rodríguez González e Manuel Lugrís Freire; e dos novos, como Roberto Blanco Torres e Antón Villar Ponte, tamén aparecía entre os seus colaboradores Emilia Pardo Bazán, autora, por exemplo, dunha

8 As 32 páxinas de que consta avalan a pertenza ao xénero novela curta, malia editarse co subtítulo "Conto". 
extensa necrolóxica, "Bardo gallego. La muerte de Eduardo Pondal" o 9 de marzo de 1917 (González Prieto 2020: 139-146).

O que nos interesa aquí é que esta novela curta de Vicente Risco leva a pegada de La sirena negra (1908), obra de fondo mítico que enlaza coa vella lenda dos Mariño, incardinada na memoria cultural galega. Pero non imos referirnos á lenda da muller ave ou peixe, devoradora de homes, senón á aparición do motivo da Danza da Morte no soño goyesco que Gaspar de Montenegro ten mentres vela a moribunda Rita Quiñones. Consiste na descrición dun paramento de existencia real, pois forma parte do legado da familia de Pardo Bazán ao Museo de Belas Artes da Coruña para a súa exposición pública. Mergulladas no soño delirante, as figuras deste tapiz tardogótico, datado entre o s. XVI e o s. XVII, cobran movemento no texto literario. Trátase dunha écphrase agochada por un símil retórico que fai revivir a danza ao longo de case vinte páxinas:

Tan doliente paisaje ofrecía los tonos secos mitigados y polvorientos de los antiguos tapices, y las figuras que sobre el paisaje comenzaron á desfilar en caricaturesca procesión, de tapiz eran también: de tapiz ó de orla de códice cuatrocentista. El cuadro era del número de los espantos que el arte ha querido agregar á los espantos de la naturaleza. (...)

Cogidos de la mano, empujados por la sobrehumana ley, contra la cual no vale resistencia, alzando los pies juveniles ó gotosos, meneando los troncos flacos ó tripones, castañeteando los dedos rígidos, retorciéndose como debían de retorcerse los Ardientes, en su rostro de martirio y locura, la multitud baila, baila, siguiendo al esqueleto que marca el compás y guía hacia el profundo agujero ó sima abierto en mitad de la llanura, donde las parejas, alzando todavía la pierna para un trenzado, caen precipitadas. (Pardo Bazán 1908: 65-66, 72)

Cómpre reparar en que o protagonista rexeita momentaneamente a escena do seu delirio por medieval, trasnoitada e triste: el prefire gozar coas sensacións que expresa unha arte nova, propia da Fin de Século: “¡En nuestros tiempos hemos reemplazado la danza macabra por la danza griega de las ninfas y faunos, ronda jocunda, símbolo de la alegría de vivir!
Anticuada está la procesión de la Seca...” (Pardo Bazán 1908: 74).

Risco admira o tema artístico da danza da morte, tal como Pardo Bazán o leva con óptica decadentista e macabra a esta novela de personaxe desquiciado por una obsesión que atrae cara a si e aos demais a traxedia. Por iso toma o motivo e transfórmao en núcleo do seu relato de 1919, que non é outro que unha reflexión estética sobre o rescate do grotesco medieval pola arte nova: "O feito real e verdadeiro da Danza Macabra (k) foi coñecido sen dúbida por algún visionario da Edade Media e quedou na lenda e no arte, mais com'o tomaron n'un senso simbólico, as xentes trabucáronse" (Risco 1919: 20-21).

Como a noveliña xoga co humor nun contexto paródico das ciencias ocultas, un dos recursos que emprega o autor a tal fin é a mestura de rexistros da escrita: o literario no corpo da novela e o propio do ensaio científico nas notas; así como a mestura de niveis diastráticos na citación de voces: os coloquialismos combínanse cunha linguaxe de cortesía ou cun rexistro solemne propio do momento climático do relato. A alusión directa a Emilia Pardo Bazán preséntase nunha nota a pé de páxina referida á cita que acabamos de facer e que certifica o modelo que toma Risco para a súa creación: “k) O leutor atopará unha manífica descrición da Danza Macabra polo xeito das conceuciós da Edade Media, na novela La sirena negra da Condesa de Pardo Bazán" (Ibid.: 21).

Risco constrúe o relato arredor deste tema e da explicación ocultista da roda de esqueletos danzantes. O personaxe de Dehmel, condutor de Alveiros ata o ultramundo habitado polo corpo astral tras a morte física, ten que cumprir unha tarefa encomendada polo coreógrafo libio Chubu, morto hai miles de anos e levado un día a un museo do Cairo onde o colocan xunto ao sarcófago de Tutankamón ${ }^{9}$. E alí decátase de que o esqueleto exipcio devece por participar na danza da morte, pero non pode porque o envolven faixas con rescritos de encantamentos que as fan indestrutibles, a non ser que alguén con dominio da maxia atope unha maneira de logralo. Alveiros, ocultista, atopa a maneira. Chubu explícalle que a Danza Macabra é un baile feliz, no que os esqueletos

9 O autor adianta literariamente a descuberta do sarcófago, que tivo lugar en 1922 (Rodríguez González 2002: 421, $750)$. 
festexan o despoxamento da carne corrompida. A noveliña ofrece entón unha descrición da danza con alardes de linguaxe rítmica próxima á vangarda:

¿Y-aquel-era a Danza Macabra dos visionarios medievales? ¿Y-en que s'imitaba aquela prodixosa festa onde todol-os sensos eran agarimados pol-as mais doces sensaciós d'arte e de gozo ôs terroríficos monicreques d'Holbein e mais do vello Brueghel? ¿Que tiña que ver aquelo co-a estupeda artificiosidade seud'artistica que Saint Saens s'estreveu a chamar Danza Macabra...? (...)

Enton viu a danza xeral, delirante, louca, tola, frenética: Os esqueletes brincaban, corrían, botaban un atrás do outro, facían roda como fan as bruxas, e daban voltas com'os derviches volteadores, rían berraban aturuxaban, faguend'un rebumbio que deixaba xordo a un, y-ô que faguía acompañamento a orquesta cun prestíssimo que facía tolear...

Alveiros y-o far[a]ón collidos da man metéronse no medio do baile y-a loucura durou hastra que, por riba do inmenso estrondo, ergueuse com'a trompeta do Xuicio Final...

\section{O CANTO DO GALO}

(Risco 1919: 28, 30)

Para rematar con esta segunda proba da presenza de Pardo Bazán na narrativa galega do seu tempo, diremos que hai un antes e un despois na atención de Vicente Risco á autora coruñesa. $\mathrm{O}$ escritor formárase intelectualmente no parladoiro da Comisión de Monumentos de Ourense con Marcelo Macías e Arturo Vázquez Núñez, entre outros intelectuais, que consideran a Pardo Bazán escritora insigne e a acompañan nas súas visitas á cidade (Redacción El Miño 1901). Nos preliminares da dedicación de Vicente Risco á prensa, a arte e á literatura decadente e modernista en termos que expresaría no manifesto Preludio a toda estética futura (1917-1918), hai dous artigos de 1911 en Mi Tierra sobre a literatura galega. No segundo, diagnostica o seu acabamento e refuxio na literatura popular, unha vez rematado o Renacemento do s. XIX. Nesta apreciación coincide con outros estudosos, como o propio director da publicación, Eugenio López Aydillo. Risco escribe que a mellor literatura galega nese momento se está a facer en castelán, con Emilia Pardo Bazán e Ramón del Valle inclán como representantes eximios. A afirmación provoca a resposta dun rexionalista, Ayras, desde Compostela. Ao polemizar con el, Risco asegura que non só o idioma fai "Galicia", pois están "la raza, el ambiente, las creencias, la historia” (Risco, apud Rodríguez González 2002 [1993]: 271).

Pouco máis de sete anos despois, estas mesmas palabras servirían de acicate para, tomando o temón nas propias mans e das do grupo Nós, que se encargase Risco de que esa lingua galega volvese ser digna dunha literatura culta. Daquela, conviña, como vimos, afastar cara aos bordos do canon, por alleos ao compromiso co galego na escrita literaria, os antigos mestres. Pero tratábase dunha estratexia político-cultural tan necesaria como eventual. Volverían ser requiridos ao campo cultural propio. Velaí Castelao, que en Un ollo de vidro. Memorias d'un esquelete (1922) entraría pouco despois de Risco no tema do macabrismo post-mortem; que deseñaría os decorados para a estrea de Divinas Palabras de Ramón del Valle Inclán no Madrid de 1933; e que incluiría Emilia Pardo Bazán na súa locución no exilio de Buenos Aires, Alba de Gloria (1948). Velaí Vicente Risco relendo a autora e escribindo no xornal La Región e na revista Posío, ambos de Ourense, sobre ela e Galicia, co gallo da conmemoración do centenario do nacemento en 1951. Buscaba na relectura da narrativa de Pardo Bazán información etnográfica e sinalaba que fora unha figura clave na literatura de Galicia, anticipándose en varias correntes novas, desde a atención ao panorama coevo da cultura europea ata o modernismo, pasando pola utilización do folclore na narrativa.

\section{Consideracións finais}

O encetamento da confrontación ideolóxica polo modelo de Estado a raíz da cuestión catalá e a perda de Cuba e outras colonias do antigo imperio español non supón, no primeiro dos casos vistos neste traballo, unha pexa importante para os contactos e trasvases literarios entre escritores e escritoras que compartían un tempo histórico e un espazo de socialización literaria comúns.

Emilia Pardo Bazán colocouse fronte á literatura galega cando tomou parte, a raíz do chamado Desastre, no proxecto político rexeneracionista de nación española castelán-centrista. Ata 1885-1888 enfrontárase por razóns morais e de clase, ideolóxicas e mesmo persoais con M. Curros Enríquez, vítima da represión da carcunda tradicionalista de Ourense; e con M. Murguía, preterido polos historiadores krausistas e mesmo polo A. Machado Álvarez a causa 
das súas teses como historiador de Galicia. Pero non se enfrontou con Eduardo Pondal, Benito Losada ou Valentín Lamas Carvajal.

Pardo Bazán foi testemuña privilexiada do custoso proceso de consolidación da literatura galega rexurdida anos atrás, a través das tres canles do proxecto rexenerador do rexionalismo, que era literario e non só político, como revela a actividade dos tres líderes: o liberal progresista de Manuel Murguía, o tradicionalista e moi próximo ao nacionalismo futuro de Alfredo Brañas e o federalista de Aureliano Pereira. Formouse e fíxose escritora en Galicia, e medrou no ambiente dos parladoiros e actividades culturais, moitas das cales ela terminaría liderando (Rodríguez González 2009: $647,652,657)$. Esa rica e complexa rede de sociabilidade cultural converteuna, malia todas as resistencias para establecer os marcos da literatura nacional e a literatura rexional, en elemento canónico dinámico. Érao, de feito, nas primeiras historias da literatura galega, como a que ofrece o devandito Alfredo Brañas no capítulo "Historia del Renacimiento de la literatura gallega" de El Regionalismo (1889), ou nas series de artigos do mesmo teor que ofrece A. Pereira na Revista de España, nos que os xuízos críticos e a obra de Pardo Bazán son moi tidos en conta (Pereira 1892).

Cando o segundo rexurdimento político e cultural galego nace en plena guerra mundial e un novo mapa europeo termina deseñándose ao abeiro da Sociedade das Nacións, a novela galega xorde coa conciencia de marcar a diferenza respecto da cultura imperante e con ansia de renovación a través das vangardas europeas, que van incorporarse directamente, sen intermediación da cultura castelá. Con todo, os referentes da literatura española semella que non deixaron de usarse cando conviña, quedando para a propaganda política a exacerbación do diferencialismo e a reivindicación da cultura galega sen aculturacións.

Por iso non estraña a reacción de Antón Villar Ponte, vello colaborador tamén na revista galego-cubana Follas Novas, á parte de articulista de El Noroeste, cando pouco despois de fundar as Irmandades da Fala na Coruña, respondía a certas declaracións da escritora co gallo do Certame de Arte Galega celebrada en 1917 na cidade. Afirmaba nelas a existencia dunha "raza común hispana, da que todal-as manifestaciós rexionás d'orde artístico non son senón xeitos d'estructura acidental". Tras rebatela, despedíase dela Villar Ponte deste xeito: "nosa ilustre enimiga a quen lle bico os pes" (González Prieto 2020: 275, 277).

Con estas dúas demostracións da influencia de Emilia Pardo Bazán na narrativa galega coeva acabamos de comprobar que, na análise comparada ibérica do período 1899-1919, se recoñecen as tensións entre un protosistema literario de forte heteronomía como o galego e un sistema literario español en crise a esas alturas tanto por esgotamento de estética e de lingua literaria como pola situación tamén de heteronomía que provocara a encrucillada entre dous modelos políticos de construción do Estado.

\section{Referencias bibliográficas}

Alonso Montero, Xesús (1977): "Pra unha biografía de Xan da Masma”, en Lengua, literatura e sociedade en Galicia. Madrid: Akal, pp. 132-134.

Carballo Calero, Ricardo (1981): Historia da literatura galega contemporánea (1808-1936). Vigo: Galaxia. Carré Aldao, Eugenio (1911² [1903]): Literatura Gallega. Barcelona: Casa Editorial Maucci.

Fernández-Merino, José (1900): “Galicia en Cuba”, El Eco de Galicia 313 (Buenos Aires) 30/06/1900, pp. 3-4, https://biblioteca.galiciana.gal/es/publicaciones/numeros_por_mes.do?idPublicacion=105\&anyo=1900 [consulta: 04/11/2021].

González Prieto, Manuel (ed.) (2020): A literatura galega na ollada de Emilia Pardo Bazán. Antoloxía de textos (Limiar de Xesús Alonso Montero). Santiago de Compostela: Real Academia Galega.

Hermida, Modesto (1993): “Noticia sobre ¡A besta!”, en «Xan de Masma»: ;A besta! Vigo: Galaxia, pp. 9-20.

Lence-Santar y Guitián, Eduardo (1925): "Carlistas prisioneros por la Guardia civil la mañana del 11 de octubre de 1872, en una casa de Cabana de Vella, a cuatro kilómetros de Mondoñedo". Foto acompañada de pé con este título, Almanaque Gallego. Año 1925 (Buenos Aires), p. 80, http://www.galiciana. bibliotecadegalicia.xunta.es/gl/catalogo_imagenes/grupo.do?path=1002610\&presentacion=pagina\&po sicion $=88$ [consulta: $04 / 11 / 2021]$.

Liga de Amigos de La Coruña (1905): Centenario del "Quijote" en Galicia. A Coruña: Talleres de fotograbado e imprenta Pedro Ferrer. 
Neira Vilas, Xosé (2011): A prensa galega de Cuba. Santiago de Compostela: Xunta de Galicia, Centro Ramón Piñeiro para a Investigación en Humanidades.

Otero Pimentel, Luis («L. de Outeiro») (1898): Campaña da Caprecórneca. Novela gallega hestóreca, fantásteca e poética. Habana: Impr. 'El Comercio Tipográfico' (Biblioteca do semanario gallego Follas Novas, da Habana), https://biblioteca.galiciana.gal/es/consulta/registro.do?id=7670 [consulta: 04/11/2021].

(19942 [1898]): A campaña da Caprecórneca (Ed. de Modesto Hermida; Com. lingüístico de Carme López Taboada). Vigo: Galaxia.

Pardo Bazán, Emilia (1888): De mi tierra. A Coruña: Tipografía de la Casa de Misericordia, http://bdh-rd. bne.es/viewer.vm?id=0000201051\&page $=1$ [consulta: 04/11/2021].

— (1908): La sirena negra. Madrid: M. Pérez Villavicencio Editor, http://bdh-rd.bne.es/viewer. vm?id=0000133436\&page=1 [consulta: 04/11/2021].

Pereira, Aureliano (1892): “Algo acerca do Movemento literario de Galicia”, Revista de España 554 (tomo 139, 03-04/1892), pp. 389-400; 555 (tomo 140, 05-06/1892), pp. 25-37; 556, pp. 146-153, http://hemerotecadigital.bne.es/details.vm?q=id:0002715600\&lang=es [consulta: 04/11/2021].

Ramil Díaz, Aurita (1998): “Aproximación á obra narrativa de Xan de Masma”, Revista Monfadal 1 (Mondoñedo), pp. 39-54.

Redacción (1900): “Don Patricio Delgado Luaces (Xan de Masma)”, Follas Novas 29/04/1900, p. 4, https:// biblioteca.galiciana.gal/es/publicaciones/numeros_por_mes.do?idPublicacion=4382\&anyo=1900 [consulta: 04/11/2021].

Redacción (1900): "Patricio Delgado Luaces", El Correo de Lugo 242, 22/05/1900, p. 3, https://biblioteca.galiciana.gal/es/publicaciones/numeros_por_mes.do?idPublicacion=75\&anyo=1900, [consulta: 04/11/2021].

Redacción (1901): “á la señora Pardo Bazán” (sic). El Miño: Diario Liberal 779, 12/06/1901, p. 2, https://biblioteca.galiciana.gal/gl/publicaciones/listar_numeros.do?busq_idPublicacion=187\&busq_dia\&busq mes $=6 \&$ busq anyo $=1901 \&$ posicion [consulta: 04/11/2021].

Risco, Vicente (1919): Do caso que ll'e acontecéu ô Dr. Alveiros. (¡Terra a nosa! Bibrioteca Popular Galega, supremento de El Noroeste 7). A Coruña.

- (1976 [1933]): Manuel Murguía. Conciencia de Galicia. Vigo: Galaxia.

Rodríguez González, Olivia (2001): “As primeiras novelas galegas editadas en Cuba”, en Dieter Kremer (ed.): Un século de Estudios Galegos. Galicia fóra de Galicia. Actas VI Congreso Internacional de Estudios Galegos. 17 a 21 de abril de 2000. Trier: Ediciós do Castro / Centro de Documentación de Galicia da Universidade de Trier, vol. 1, pp. 277-288.

_ (2002 [1993]): La obra narrativa de Vicente Risco. Tese de doutoramento. Madrid: Universidad Complutense de Madrid, http://eprints.ucm.es/3328/1/T17993.pdf [consulta: 04/11/2021].

(2009): "Emilia Pardo Bazán y la literatura gallega”, en José Manuel González Herrán, Cristina Patiño Eirín e Ermitas Penas Varela (eds.): La literatura de Emilia Pardo Bazán. A Coruña: Fundación Caixa-Galicia / Casa-Museo Emilia Pardo Bazán, pp. 647-663.

Ruíz Leivas, Xosé (2000): “Os carlistas mindonienses”, Revista Monfadal 2 (Mondoñedo), pp. 39-54.

Sánchez Pérez, Amelia (2011): “AA Besta! e o Rexionalismo galego”, en Helena Rebeno (coord.): Lusofonia: tempo de reciprocidades. Actas IX Congresso da Associação Internacional de Lusitanistas (Madeira, 4 a 9 de agosto de 2008). Porto: Afrontamento, vol 2, pp. 315-321.

«Xan de Masma» [Patricio Delgado Luaces] (1899-1900): A besta!, Follas Novas 87-187 (La Habana), https://biblioteca.galiciana.gal/gl/consulta/registro.do?id=577336 [consulta: 04/11/2021].

(19932 [1899-1900]): ;A besta! (Ed. de Modesto Hermida; Com. Lingüístico de Carme Hermida). Vigo: Galaxia. 